\title{
Mycoplasmas and ureaplasmas in patients with hypogammaglobulinaemia and their role in arthritis: microbiological observations over twenty
} years

\author{
P M Furr, D Taylor-Robinson, A D B Webster
}

\begin{abstract}
Objectives-To study the occurrence of mycoplasmas and ureaplasmas in patients with hypogammaglobulinaemia and the relationship of these micro-organisms to septic arthritis.

Methods-Over a period of about 20 years, 53 men and 38 women with hypogammaglobulinaemia, most of whom were less than 50 years old, were examined clinically and microbiologically. Mycoplasmas and ureaplasmas were sought in the throat, urogenital tract and joints by standard cultural methods, although not consistently in the three sites of all patients.
\end{abstract}

Results-Arginine-hydrolysing mycoplasmas and ureaplasmas occurred with similar frequency in the sputum/throat of the hypogammaglobulinaemic patients, but no more often than might be expected in immunocompetent patients. Ureaplasmas, however, dominated in the urogenital tracts of both men and women, being found in $\mathbf{7 5 \%}$ of vaginal specimens. Arginine-hydrolysing mycoplasmas occurred two to six times more frequently and ureaplasmas two to three times more frequently in urine specimens from hypogammaglobulinaemic patients than they did in such specimens from sex- and agematched non-venereal disease, hospital patients or healthy subjects; these differences were statistically significant $(p<0 \cdot 05)$. Enhanced mucosal colonisation probably increases the chance of spread to distant sites, such as the joints. Of the 91 patients, $21(23 \%)$ had septic arthritis involving one or more joints. Mycoplasmas and/or ureaplasmas, but not bacteria, were isolated from the joints of eight $(38 \%)$ of these patients. However, dissemination to joints apparently had not occurred in some despite the opportunity by virtue of mycoplasmal or ureaplasmal colonisation at a mucosal site. Sometimes antibiotic therapy failed clinically, and microbiologically and recommendations for management are outlined.

Conclusions-Hypogammaglobulinaemic patients appear to be more susceptible to colonisation of mucous membranes, especially of the urogenital tract, with mycoplasmas and ureaplasmas than are immunocompetent individuals. These micro-organisms are responsible for about two fifths of the septic arthritides occurring in these patients.

(Ann Rheum Dis 1994; 53: 183-187)

Members of the family Mycoplasmataceae, within the order Mycoplasmatales, are the smallest free-living organisms and are subdivided into two genera; the genus Mycoplasma (the organisms of which we term trivially, mycoplasmas) and the genus Ureaplasma which provides a separate status for the urea-hydrolysing organisms, termed trivially ureaplasmas. Ureaplasmas of human origin belong to the species, $U$ urealyticum. ${ }^{1}$ In both human and veterinary medicine mycoplasmas and ureaplasmas have predilection for mucous membranes. Hence, disease occurs primarily in the respiratory and urogenital tracts. In addition, for several animal species there is a proven association between mycoplasmas and arthritis. ${ }^{2}$ Such knowledge stimulated attempts to culture these microorganisms from the joints of patients with rheumatoid arthritis and to associate them with the disease, ${ }^{3}$ but there has never been proof of such an association.

However, there has been increasing evidence that mycoplasmas and/or ureaplasmas recovered from the joints of hypogammaglobulinaemic patients with septic arthritis are the cause of the disease. ${ }^{4-14}$ During the last 20 years we have recovered these micro-organisms from the joints of such patients, some but not all, of the information, having been reported previously. ${ }^{4-8} 10$ In addition, we determined the occurrence of these micro-organisms at other anatomical sites of the hypogammaglobulinaemic patients, and we present this information together with further evidence of their recovery from joints. Furthermore, we have compared the results of isolation from mucosal sites of both hypogammaglobulinaemic patients and immunocompetent individuals in an attempt to assess the susceptibility of patients with hypogammaglobulinaemia to mycoplasmal colonisation and hence to the risk of developing mycoplasma-induced arthritis. 


\section{Patients and methods \\ PATIENTS}

Over a period of about 20 years, 91 hypogammaglobulinaemic patients, comprising 53 males and 38 females, were examined clinically and microbiologically at the Clinical Research Centre. Most of them were below 50 years of age at first presentation, the age range of the males being 6-75 years (mean 32.5 years) and that of the females being $15-80$ years (mean 37 years). A few of the patients were examined only once but many were seen on numerous occasions during this period.

\section{SPECIMENS}

Urine, sputum and synovial fluid specimens were collected in sterile containers and delivered within an hour to the laboratory. Plain cotton-wool swabs (Medical Wire and Equipment Co, Corsham, Wilts) were used to take specimens from the throat and vagina (swab MW104) and from the urethra (swab MW142). Their contents were expressed in standard liquid medium (SLM) ${ }^{15}$ for transportation and storage. Synovial tissue samples were homogenised in SLM in a Ten-Broeck tissue grinder to produce a $10 \% \mathrm{w} / \mathrm{v}$ suspension. Not all the specimens mentioned were collected from each patient.

\section{MYCOPLASMA MEDIA}

These media have been described in detail previously..$^{15}$ In brief, liquid medium contained $70 \%$ PPLO broth (Difco) to which was added $10 \%$ yeast extract $(25 \% \mathrm{w} / \mathrm{v}), 20 \%$ horse serum, $10^{5}$ iu of penicillin, $0.05 \%$ thallium acetate and $0.002 \%$ phenol red. To this medium was added one of the following substrates and the $\mathrm{pH}$ adjusted as indicated to provide three separate media for the attempted isolation of glucose-fermenting and arginine-

Table 1 The proportion of hypogammaglobulinaemic patients in whom mycoplasmas and ureaplasmas were found in the sputum and throat

\begin{tabular}{llll}
\hline $\begin{array}{l}\text { Gender and } \\
\text { specimen }\end{array}$ & \multicolumn{2}{l}{$\begin{array}{l}\text { Proportion (\%) of patients from whom } \\
\text { indicated organisms were isolated }\end{array}$} \\
\cline { 2 - 4 } & Arg* & Ureat & Both \\
\hline Male sputum & $8 / 18(44)$ & $5 / 16(31)$ & $4 / 16(25)$ \\
Female sputum & $5 / 12(42)$ & $2 / 7(29)$ & $1 / 7(14)$ \\
Male throat & $5 / 24(21)$ & $7 / 22(32)$ & $3 / 22(14)$ \\
Female throat & $2 / 8(25)$ & $0 / 7(0)$ & $0 / 7(0)$ \\
\hline
\end{tabular}

^Arginine-metabolising mycoplasmas.

†Ureaplasmas. hydrolysing mycoplasmas and ureaplasmas, respectively: $1 \%$ glucose $(\mathrm{pH} \quad 7 \cdot 8), 2 \%$ $\mathrm{L}$-arginine hydrochloride $(\mathrm{pH} 7 \cdot 0)$ or $1 \%$ urea (pH 6.8).

DETECTION AND QUANTITATION OF ORGANISMS Serial ten-fold dilutions of specimens $(0.2 \mathrm{ml}$ in $1.8 \mathrm{ml}$ of medium) were made in the media usually to a dilution of $10^{-6}$ for ureaplasmas and $10^{-8}$ for mycoplasmas. The highest dilution at which the medium changed colour was deemed to contain one colour-changing unit (ccu). ${ }^{16}$ Specimens from joints were examined also by standard bacteriological methods for aerobic and anaerobic bacteria.

\section{Results}

MYCOPLASMAS AND UREAPLASMAS IN THE SPUTUM AND THROAT

Mycoplasmas were found almost twice as frequently in sputum as they were in throat swabs from an unselected subgroup of the hypogammaglobulinaemic patients, and they occurred equally in men and women (table 1). They were not characterised further by speciation. Ureaplasmas were detected with similar frequency, but were not detected in the throats of the women, although the number examined was small.

$M$ pneumoniae was isolated from sputum and/or throat swab specimens from one ${ }^{17}$ of 41 male patients, but from none of 21 female patients who were examined for this mycoplasma.

MYCOPLASMAS AND UREAPLASMAS IN THE UROGENITAL TRACT

The prevalence of both mycoplasmas and ureaplasmas in the urogenital tract of the hypogammaglobulinaemic patients, as judged by their occurrence in urine specimens, was similar in both men and women (table 2), and ureaplasmas were detected at least twice as often as the arginine-hydrolysing mycoplasmas. The dominance of ureaplasmas was seen also in swab specimens taken from the male urethra, where testing of urethral swabs proved to be about as sensitive as testing urine specimens. In contrast, in women, vaginal specimens, which contained ureaplasmas more frequently than arginine-hydrolysing mycoplasmas, were positive more often than the urine specimens.

Table 2 The proportion of hypogammaglobulinaemic patients in whom mycoplasmas and ureaplasmas were found in urogenital-tract specimens

\begin{tabular}{|c|c|c|c|c|c|c|c|c|c|c|}
\hline \multirow[t]{2}{*}{ Gender } & \multirow[t]{2}{*}{ Specimen } & \multirow[t]{2}{*}{$\begin{array}{l}\text { No } \\
\text { tested }\end{array}$} & \multicolumn{3}{|c|}{$\begin{array}{l}\text { No }(\%) \text { of patients with indicated } \\
\text { organism }\end{array}$} & \multirow[t]{2}{*}{ Specimen } & \multirow[t]{2}{*}{$\begin{array}{l}\text { No } \\
\text { tested }\end{array}$} & \multicolumn{3}{|c|}{$\begin{array}{l}\text { No (\%) of patients with indicated } \\
\text { organism }\end{array}$} \\
\hline & & & $\operatorname{Arg}^{*}$ & Ureat & Both & & & Arg & Urea & Both \\
\hline Male & Urine & 15 & $3(20)$ & $7(47)$ & $3(20)$ & $\begin{array}{l}\text { Urethral } \\
\text { swab }\end{array}$ & 16 & $2(12 \cdot 5)$ & $7(44)$ & $2(12 \cdot 5)$ \\
\hline Female & Urine & 16 & $4(25)$ & $9(56)$ & $4(25)$ & $\begin{array}{l}\text { Vaginal } \\
\text { swab }\end{array}$ & 12 & $6(50)$ & $9(75)$ & $6(50)$ \\
\hline
\end{tabular}

^Arginine-metabolising mycoplasmas. 
COMPARISON OF URINE FINDINGS FOR HYPOGAMMAGLOBULINAEMIC AND IMMUNOCOMPETENT PATIENTS

The results of culturing urines from men and women with hypogammaglobulinaemia are compared with the results, reported previously, ${ }^{18}$ of testing urines from a non-venereal disease, hospital patient group, and from a healthy group (table 3 ). The argininehydrolysing mycoplasmas occurred two to six times more frequently and the ureaplasmas two to three times more frequently in the hypogammaglobulinaemic patients than they did in the other two groups, differences which were statistically significant $(p<0.05)$.

\section{MYCOPLASMAS AND UREAPLASMAS ISOLATED} FROM JOINTS

Of the 91 hypogammaglobulinaemic patients examined, $21(23 \%)$ (12 men and 9 women) had septic arthritis involving one or more joints in which there were polymorphonuclear leucocytes in the synovial fluid, that is a septic arthritis. Neither aerobic nor anaerobic bacteria were detected in the specimens from

Table 3 The proportion of hypogammaglobulinaemic and immunocompetent subjects in whom mycoplasmas and ureaplasmas were found in the urine

\begin{tabular}{llllll}
\hline $\begin{array}{l}\text { Group } \\
\text { studied }\end{array}$ & Sex & $\begin{array}{l}\text { No of subjects } \\
\text { in group }\end{array}$ & \multicolumn{3}{c}{$\begin{array}{l}\text { \% of patients with indicated } \\
\text { organism }\end{array}$} \\
\cline { 3 - 6 } & & & Arg* & Urea† & Both \\
\hline Hypo $^{\star \star}$ & M & 15 & 20 & 47 & 20 \\
& F & 16 & 25 & 56 & 25 \\
Non-VD & M & 100 & 4 & 19 & 3 \\
<50 years & F & 100 & 3 & 29 & 10 \\
Normal & M & 50 & 6 & 14 & 6 \\
<50 years & F & 50 & 10 & 28 & 10 \\
\hline
\end{tabular}

^Arginine-metabolising mycoplasmas.

tUreaplasmas.

$\star \star$ Hypogammaglobulinaemic.

Table 4 Mycoplasmas and/or ureaplasmas isolated from the joints of hypogammaglobulinaemic patients with arthritis

\begin{tabular}{llll}
\hline $\begin{array}{l}\text { Mycoplasmal } \\
\text { ureaplasma }\end{array}$ & Case & \multicolumn{2}{l}{ Mycoplasma-positive joints } \\
\cline { 3 - 4 } & & Number & Site \\
\hline M pneumoniae & 1 & 3 & Thumb, ankles \\
& 2 & 1 & Knee \\
M salivarium & 3 & 1 & Elbow \\
M hominis & 4 & 1 & Knee \\
U urealyticum & $5^{\star}$ & 4 & Shoulder, elbow, wrist, knee \\
& 6 & 3 & Shoulder, wrist, knee \\
& 7 & 1 & Finger \\
& 8 & 1 & Knee \\
\hline
\end{tabular}

^Also $M$ hominis from shoulder and elbow.

Table 5 Summary of the occurrence of mycoplasmas and ureaplasmas at various sites of, or in specimens from, hypogammaglobulinaemic patients

\begin{tabular}{|c|c|c|c|c|}
\hline \multirow{3}{*}{$\begin{array}{l}\text { Site or } \\
\text { specimen } \\
\text { tested }\end{array}$} & \multicolumn{4}{|c|}{ Percentage of patients from whom mycoplasmas or ureaplasmas were isolated } \\
\hline & \multicolumn{2}{|c|}{ Male } & \multicolumn{2}{|c|}{ Female } \\
\hline & Mycoplasmas & Ureaplasmas & Mycoplasmas & Ureaplasmas \\
\hline Throat & $21 \%$ & $32 \%$ & $25 \%$ & $0 \%$ \\
\hline Sputum & $44 \%$ & $31 \%$ & $42 \%$ & $29 \%$ \\
\hline Ưrine & $20 \%$ & $47 \%$ & $25 \%$ & $56 \%$ \\
\hline Urethra & $12 \cdot 5 \%$ & $44 \%$ & - & - \\
\hline Vagina & - & - & $50 \%$ & $75 \%$ \\
\hline Joints & $25 \%$ & $33 \%$ & $22 \%$ & $0 \%$ \\
\hline
\end{tabular}

these joints. However, mycoplasmas and/or ureaplasmas were isolated from the joints of eight $(38 \%)$ of the arthritic patients; the details are shown in table 4 . Ureaplasmas were recovered most frequently, occurring in half of the patients who had organisms in the joints.

MYCOPLASMAS AND/OR UREAPLASMAS AT OTHER ANATOMICAL SITES OF JOINT-POSITIVE AND -NEGATIVE PATIENTS

Of the eight patients whose joint specimens were positive for mycoplasmas and/or ureaplasmas, seven were sampled from one or more other sites (throat, urethra, vagina); of these, five $(71 \%)$ were positive, the organisms corresponding to those found in the joints. Of the 13 patients whose joint specimens were negative, seven were sampled from one or more other sites; of these, three ( $43 \%)$ were positive. In comparison, of 41 men with hypogammaglobulinaemia who did not have arthritis, mycoplasmas and/or ureaplasmas were isolated from one or more non-articular sites of 15 ( $37 \%$ ), and of 29 such women, these microorganisms were isolated from one or more nonarticular sites of $13(45 \%)$.

The occurrence of these micro-organisms at the various anatomical sites examined in this study is summarised in table 5 .

\section{Discussion}

Since previous work had shown that mycoplasmas and/or ureaplasmas were a cause of septic arthritis in hypogammaglobulinaemic patients, it was of interest to analyse all the cases seen and determine the extent to which these micro-organisms existed in the probable primary sites of infection, that is, the respiratory and/or urogenital tracts from which they were able to disseminate to the joint(s). It should be appreciated that this was not a planned prospective study in which specimens were taken from all possible sites each time a patient was seen over the 20 -year period. The data therefore are fragmentary, but nevertheless informative and are summarised in table 5. The tendency for mycoplasmas to be found more often in sputum than throat specimens may be due to inadequate swabbing. Overall, the prevalence of argininehydrolysing mycoplasmas in the sputum and throat was certainly no greater than might be expected in immunocompetent patients. ${ }^{19}$ Conversely, the prevalence of ureaplasmas was greater, but the results were in keeping with those of others ${ }^{20}$ who have examined the respiratory tract of hypogammaglobulinaemic patients. Ureaplasmas were found by us even more frequently in the urogenital tract of such patients. These organisms, and mycoplasmas, were particularly common in women. It is likely that the vagina is the preferential site of colonisation and that many of the organisms recovered from the urine resulted from contamination of the specimens from the vagina.

It should be emphasised that the samples from the hypogammaglobulinaemic patients 
had been collected over a period of 20 years and that the sexual orientation, number of lifetime sexual partners and other demographic details of these patients were unknown. We compared the results of mycoplasmal isolation from the urine of these patients with those, reported previously, ${ }^{18}$ of similar isolation attempts, over a short period, from groups of sex- and age-matched immunocompeten individuals for whom other demographic details were lacking. It is difficult therefore to know exactly how valid the comparison is, but on this basis, the mycoplasmas and ureaplasmas occurred apparently much more frequently at mucosal sites in the hypogammaglobulinaemic patients. The absence of protective antibody at the mucosal surfaces ${ }^{21}$ could account for increased susceptibility to colonisation. Of course, more frequent colonisation at mucosal sites in the hypogammaglobulinaemic patients than in immunocompetent individuals, often with large numbers of organisms, would increase the opportunity for organisms to disseminate to distant sites, such as the joints and even bone. ${ }^{22}$ There is also a suggestion that patients who developed arthritis had mycoplasmas and/or ureaplasmas at a non-articular site more often than did those who did not develop arthritis, but the number of patients examined is too small to be sure of this point. The absence of, or reduced levels of antibody in the hypogammaglobulinaemic patients is also a factor in the enhanced ability of the organisms to spread. Mycoplasmas and/or ureaplasmas were detected by us in the joints of about twofifths of such patients who were examined when they had an acute attack of septic arthritis. None of them had a bacterial infection of the joint. Whether any of the apparently mycoplasma- or ureaplasmanegative arthritides were due to these microorganisms (our culture attempts having failed perhaps due to previous antibiotic therapy) is a moot point. Almost half of these patients appear to have had the organisms colonising a mucosal surface at the time they had arthritis. In addition, some disease may have been due to mycoplasmas which we did not seek. Those, such as, Mycoplasma genitalium and $M$ fermentans, are extremely difficult to isolate but may be detected by the much more sensitive polymerase chain reaction that has become available more recently. ${ }^{23}{ }^{24}$ It is possible that following an initial insult, mycoplasmas and/or ureaplasmas may remain in a non-viable form, as shown for Chlamydia trachomatis in sexually acquired reactive arthritis. ${ }^{25}$

During these observations, it became evident that most patients responded clinically to antibiotic therapy, but a few did not. In these patients, recovery of the organisms continued despite the fact that they were sensitive as indicated by in vitro susceptibility testing. ${ }^{10}$ The recent discovery that some species of mycoplasmas have the ability to enter epithelial cells $^{26} 27$ may help to explain the difficulty of eradicating them. In such cases too, antibiotic resistance developed rapidly and there may be value in always treating with more than one antibiotic in an attempt to counter this effect. In the recalcitrant cases, clinical improvement appeared to be brought about by administration of antiserum prepared specifically against the mycoplasma in question. ${ }^{10}$ Our experience leads us to suggest that: (1) the likelihood of mycoplasmal involvement should always be considered in arthritis developing in hypogammaglobulinaemic patients, particularly when attempts to isolate bacteria from synovial fluids and/or tissues by routine bacteriological methods have failed; (2) the isolate should be tested immediately against a wide range of antibiotics in vitro; (3) the most inhibitory antibiotic should be given as soon as possible by the most appropriate route (intravenously, if possible); (4) such therapy should be prolonged and terminated only if there is no reasonably rapid clinical and/or microbiological response, and (5) thought should be given to the administration of a specific antiserum, perhaps together with antibiotics, in those cases that do not respond. Gelfand $^{28}$ has recommended the use of intravenous immunoglobulin with a high titre of antibody for eradication or prevention of infection in hypogammaglobulinaemic patients.

The data presented here were collected from patients with hypogammaglobulinaemia, but these organisms occur also in those undergoing immunosuppressive chemotherapy ${ }^{29} 30$ and our recommendations for therapy could also prove valuable for these patients.

1 Shepard M C, Lunceford C D, Ford D K, et al. Ureaplasma urealyticum gen nov sp nov. Proposed nomenclature for the human (T-strain) mycoplasma. Int $\mathcal{f}$ System Bacteriol 1974; 24: 160-71.

2 Cole B C, Washburn L R, Taylor-Robinson D. Mycoplasma-induced arthritis. In: Razin $S$ and Barile $M F$ plasma-induced arthritis. In: Razin S and Barile M F, eds. Mycoplasma Pathogenicity. The Mycoplas

3 Williams $M$ H, Brostoff J, Roitt I M. Possible role of Mycoplasma fermentans in pathogenesis of rheumatoid arthritis. Lancet 1970; ii: 277-80.

4 Webster A D B, Taylor-Robinson D, Furr P M Asherson G L. Mycoplasma (ureaplasma) septic arthritis in hypogammaglobulinaemia. $B M \mathscr{f} 1978$; i: 478-9.

5 Stuckey M, Quinn P A, Gelfand E W. Identification of Ureaplasma urealyticum in a patient with polyarthritis. Lancet 1978; ii: 917-20.

6 Taylor-Robinson D, Gumpel J M, Hill A, Swannell A J. Isolation of Mycoplasma pneumoniae from the synovial fluid of a hypogammaglobulinaemic patient in a survey of patients with inflammatory polyarthritis. Ann Rheum Dis 1978; 37: 180-2.

7 Johnston C L W, Webster A D B, Taylor-Robinson D, Rapaport G, Hughes G R V. Primary late-onset common vapaport G, Hughes G R V. Primary late-onset common inflammatory polyarthritis and septic arthritis due to inflammatory polyarthritis and septic arthritis due to
Mycoplasma pneumoniae. Ann Rheum Dis 1983; 42: 108-10.

8 So A K L, Furr P M, Taylor-Robinson D, Webster A D B Arthritis caused by Mycoplasma salivarium in hypogammaglobulinaemia. $B M \mathcal{F}$ 1983; 286: 762-3.

9 Vogler L B, Waites K B, Wright P F, Perrin J M Cassell G H. Ureaplasma urealyticum polyarthritis in agammaglobulinemia. Pediat Infect Dis 1985; 4: 687-91.

10 Taylor-Robinson D, Furr P M, Webster A D B. Ureaplasma urealyticum infection in the immunocompromised host. Pediat Infect Dis 1986; 5 Suppl: 236-8.

11 Kraus V B, Baraniuk J N, Hill G B, Allen N B. Ureaplasma urealyticum septic arthritis in hypogammaglobulinaemia. urealyticum septic arthritis in hyp

12 Jorup-Rönström C, Ahl T, Hammarström L, Smith C I E Rylander M, Hallander H. Septic osteomyelitis and polyarthritis with ureaplasma in hypogammapolyarthritis with ureaplasma in

13 Lehmer R R, Andrews B S, Robertson J A, Stanbridge E J, de la Maza L, Friou G J. Clinical and biological characteristics of Ureaplasma urealyticum induced polyarthritis in a patient with common variable polyarthritis in a patient with common variable 574-6. 
14 Lee A H, Ramanujam T, Ware P, et al. Molecular diagnosis of Ureaplasma urealyticum septic arthritis in a patient with hypogammaglobulinemia. Arthr Rheum 1992; 35: 443-8.

15 Taylor-Robinson D, Furr P M. Recovery and identification of human genital tract mycoplasmas. Isr $\mathcal{F}$ Med Sci 1981; 17: 648-53.

16 Taylor-Robinson D, Purcell R H. Mycoplasmas of the human urogenital tract and oropharynx and their possible Roy Soc Med 1966; 59: 1112-6.

17 Taylor-Robinson D, Webster A D B, Furr P M, Asherson G L. Prolonged persistence of Mycoplasma pneumoniae in 171-5.

18 Furr P M, Taylor-Robinson D. Prevalence and significance of Mycoplasma hominis and Ureaplasma urealyticum in the urines of a non-venereal disease population. Epidem Inf 1987; 98: 353-9.

19 Somerson N L, Cole B C. The mycoplasma flora of human and nonhuman primates. In: Tully J G and Whitcomb R F, eds. Human and Animal Mycoplasmas. The Mycoplasmas, vol 2. New York: Academic Press, 1979: 191-216.

20 Roifman C M, Rao C P, Lederman H M, Lavi S, Quinn P, Gelfand E W. Increased susceptibility to Mycoplasma infection in patients with hypogammaMycoplasma infection in patients with

21 Webster A D B, Furr P M, Hughes-Jones N C, Gorick B D, Taylor-Robinson D. Critical dependence on antibody for defence against mycoplasmas. Clin Exp Immunol 1988; 71: 383-7.
22 Mohiuddin A A, Corren J, Harbeck R J, Teague J L, Volz M, Gelfand E W. Ureaplasma urealyticum chronic osteomyelitis in a patient with hypogammaglobulinemia. f Allergy Clin Immunol 1991; 87: 104-7.

23 Palmer H M, Gilroy C B, Furr P M, Taylor-Robinson D. Development and evaluation of the polymerase chain reaction to detect Mycoplasma genitalium. FEMS Microbiol Letts 1991; 77: 199-204.

24 Katseni V L, Gilroy C B, Ryait B K, et al. Mycoplasma fermentans in individuals seropositive and seronegative for fermentans in individuals seroposit.

25 Keat A, Thomas B, Dixey J, Osborn M, Sonnex C, Taylor-Robinson D. Chlamydia trachomatis and reactive arthritis: the missing link. Lancet 1987; i: 72-4.

26 Taylor-Robinson D, Davies H A, Sarathchandra P, Furr $\mathbf{P}$ M. Intracellular location of mycoplasmas in cultured cells demonstrated by immunocytochemistry and electron microscopy. Int $\mathcal{f}$ Exp Path 1991; 72: 705-14.

27 Lo S-C, Hayes M M, Wang R Y-H, Pierce P F, Kotani H, Shih J W-K. Newly discovered mycoplasma isolated from patients infected with HIV. Lancet 1991; ii: 1415-8.

28 Gelfand E W. Unique susceptibility of patients with antibody deficiency to myocplasma infection. Clin Infect Dis 1993; 17 (Suppl 1): 250-3.

29 Cimolai N. Mycoplasma pneumoniae in the immunocompromised host. Chest 1992; 102: 1303-4.

30 Meyer R D, Clough W. Extragenital Mycoplasma hominis infections in adults: emphasis on immunosuppression. Clin Infect Dis 1993; 17 (Suppl 1): 243-9. 